\title{
Nutritious and delicious? Consumer perspectives on Cheddar Cheese vs the dietary nutrient contribution of cheddar in Ireland
}

\author{
E.L. Feeney ${ }^{1}$, A. Regan ${ }^{2}$, P. Wall ${ }^{2}$ and E.R. Gibney ${ }^{1}$ \\ ${ }^{1}$ UCD Institute of Food and Health, Science Centre South, Belfield, Dublin, Republic of Ireland and ${ }^{2} U C D$ School of \\ Public Health, Physiotherapy, \& Population Science, Woodview House, Belfield, Dublin, Republic of Ireland
}

Cheese is a source of many nutrients, both beneficial for health, and nutrients of concern, such as salt and fat. For these reasons, cheese is often portrayed as an unhealthy food ${ }^{(1,2)}$. A recent UK study of the salt content of supermarket cheeses appears to support this negative image, describing cheese as a 'significant' source of dietary salt ${ }^{(3)}$. However, the overall dietary intake must be considered when examining the contribution of a food to the diet. Since cheddar cheese is the most commonly-consumed cheese in Ireland ${ }^{(4,5)}$ this study aimed to (1) Examine Irish consumer perceptions of the nutrition content of cheddar cheese, and (2) To separately examine selected dietary nutrient density across high, medium and low consumers of cheddar cheese, using data from the recent National Adult Nutrition Survey (NANS).

A short online questionnaire was administered to 501 participants in Ireland to obtain data on their health perceptions of cheddar cheese, as part of the Food Reformulation for Consumers (FORC) project. Using the NANS data, mean daily intake of nutrients were calculated. Mean daily intakes of cheddar were used to group participants; into non-consumers and three equal groups designated low, medium and high.

The majority of participants held a positive health image of cheddar cheese. $76 \%$ agreed with the statement that cheddar cheese is 'nutritious', $66 \%$ of the population considered cheddar as 'safe', while $57 \%$ of those questioned said that they considered cheddar cheese as 'healthy'. There was a prevalent belief that cheddar is high in calcium, but also high in calories. Age and gender affected the responses, with older participants more likely to hold a positive health image of cheddar overall, while females were more likely to view cheddar as 'high in saturated fat', and 'high in calories'. Considering intakes, high consumers of cheddar had greater calcium intakes (per 10MJ), and greater \% energy from fat. Intakes of riboflavin and Vitamin B12 were lower in the high cheddar consumers. Sodium intake per $10 \mathrm{MJ}$ did not differ across the groups of cheddar consumption. These data show that public perceptions of cheddar are positive among most consumers and do not support cheddar as a major contributor to dietary sodium intakes in Ireland.

\begin{tabular}{|c|c|c|c|c|c|c|c|c|}
\hline & \multicolumn{2}{|c|}{ Non-consumers $n 683$} & \multicolumn{2}{|c|}{ Low $n 270$} & \multicolumn{2}{|c|}{ Medium $n 273$} & \multicolumn{2}{|c|}{ High $n 274$} \\
\hline & Mean & $\mathrm{SD}$ & Mean & SD & Mean & $\mathrm{SD}$ & Mean & SD \\
\hline$\%$ energy $(\mathrm{CHO})^{* *}$ & $46 \cdot 7^{\mathrm{a}}$ & 7.5 & $46 \cdot 5^{\mathrm{a}}$ & $6 \cdot 9$ & $45 \cdot 0^{\mathrm{b}}$ & $7 \cdot 2$ & $43 \cdot 2^{\mathrm{c}}$ & $7 \cdot 0$ \\
\hline$\%$ energy (Protein)** & $17 \cdot 4^{\mathrm{a}}$ & $3 \cdot 9$ & $16 \cdot 5^{\mathrm{b}}$ & $3 \cdot 6$ & $16 \cdot 6^{\mathrm{b}}$ & $3 \cdot 2$ & $16 \cdot 6^{\mathrm{b}}$ & $3 \cdot 2$ \\
\hline$\%$ energy $(\mathrm{Fat})^{* *}$ & $32.7^{\mathrm{a}}$ & $6 \cdot 5$ & $33 \cdot 1^{\mathrm{a}}$ & $6 \cdot 4$ & $34 \cdot 8^{\mathrm{b}}$ & $6 \cdot 0$ & $35 \cdot 4^{\mathrm{b}}$ & $6 \cdot 1$ \\
\hline Nutrients Per $10 \mathrm{MJ}$ : & & & & & & & & \\
\hline $\mathrm{Na}(\mathrm{mg})$ & 3013 & 769 & 2939 & 626 & 3026 & 650 & 3004 & 616 \\
\hline $\mathrm{Ca}(\mathrm{mg})^{* *}$ & $1034 \cdot 9^{\mathrm{a}}$ & 324.9 & $1049 \cdot 3^{\mathrm{a}}$ & 309 & $1094 \cdot 8^{\mathrm{a}}$ & $306 \cdot 9$ & $1205 \cdot 5^{\mathrm{a}}$ & 306 \\
\hline $\mathrm{Mg}(\mathrm{mg})^{* *}$ & $350 \cdot 5$ & $80 \cdot 0$ & $340 \cdot 5$ & $74 \cdot 7$ & $332 \cdot 8$ & $69 \cdot 2$ & 318.9 & $62 \cdot 2$ \\
\hline $\mathrm{K}(\mathrm{mg})^{* *}$ & 3.9 & $0 \cdot 8$ & 3.7 & 759.9 & $3546 \cdot 4$ & $725 \cdot 1$ & $3394 \cdot 3$ & 788.2 \\
\hline Vitamin B12* & $7 \cdot 2^{\mathrm{a}}$ & $6 \cdot 9$ & $6 \cdot 32^{\mathrm{b}}$ & 3.6 & $6 \cdot 3^{\mathrm{b}}$ & 4.6 & $6 \cdot 3^{\mathrm{b}}$ & $3 \cdot 1$ \\
\hline Riboflavin $(\mathrm{g}) *$ & $2 \cdot 3$ & $0 \cdot 9$ & $2 \cdot 3$ & $0 \cdot 8$ & $2 \cdot 2$ & 0.7 & $2 \cdot 2$ & $0 \cdot 6$ \\
\hline
\end{tabular}

Mean values were significantly different across groups (ANOVA, followed by Bonferroni), $* \mathrm{P}<0 \cdot 05, * * \mathrm{P}<0 \cdot 01$

1. Hope J. The Daily Mail (2014) $6^{\text {th }}$ August

2. Elkins L. The Daily Mail (2011) $25^{\text {th }}$ October.

3. Hashem KM, He FJ, Jenner KH et al. (2014) BMJ Open, 4:8.

4. IUNA (2012) National Dairy Council.

5. IUNA (2014) National Dairy Council. 